Chimia 46 (1992) 93-95

(C) Schweiz. Chemiker-Verband; ISSN $0009-4293$

\section{New Pyridine Derivatives from Essential Oils}

\section{Bruno Maurer* and Arnold Hauser}

Abstract. Four new pyridines $\mathbf{1}-\mathbf{4}$ have been isolated from jonquil absolute and their structures confirmed by synthesis. These pyridines also occur in other essential oils. abs. and were, therefore, isolated from this source by prep. GC.

The ${ }^{1} \mathrm{H}-\mathrm{NMR}$ spectrum of the first compound confirmed the empirical formula $\mathrm{C}_{9} \mathrm{H}_{11} \mathrm{~N}(11 \mathrm{H}$-atoms) and suggested the structure 1: the 3-substituted pyridine ring was indicated by four signals $(1 \mathrm{H}$ each) at $7.25,7.57,8.44$, and $8.53 \mathrm{ppm}$, whereas the remaining signals were in good agreement with a (Z)-but- 1-enyl side chain (coupling between the olefinic protons $11.5 \mathrm{~Hz}$ ).

The structure was confirmed by synthesis (Scheme 1). The Wittig reaction of 3-pyridinecarbaldehyde (5) with tri-

\section{Introduction}

For many decades, the Geneva-based perfume and flavour company Firmenich has invested considerable research effort into the chemical analysis of essential oils and other perfume and flavour materials of natural origin. The discovery of many organoleptically interesting compounds, today important chemicals widely used by the flavour and perfume industry, can be traced back to the analysis of natural products. Well-known examples are Hedione $e^{(\mathbb{R}}$, Furaneo $^{\circledR}$, Damascenone and the Damascones.

Continuing this tradition, we have analyzed the basic fractions extracted from several commercial essential oils and absolutes: jonquil abs. (Narcissus jonquilla L.), narcissus abs. (Narcissus poeticus L.), cardamom oil (Elettaria cardamomum MATON), petitgrain oil (Citrus auranticum, ssp. amara ENGL.), and patchouli oil (Pogostemon patchouli Pellet.). We were intrigued by the fact that analysis by $\mathrm{GC} /$ MS of the aforementioned basic fractions revealed the presence of the same unknown compound in each of the five samples.

The mass spectrum (Fig. I) indicated a molecular weight of 133 .

Two samples (jonquil and patchouli) contained a second unknown of longer retention time whose mass spectrum (Fig. 2) suggested a molecular weight of 175 . This second compound was probably a higher homologue of the first, although no intermediate members of the series were detected.

\section{Results and Discussion}

Both compounds, $\mathbf{1}$ and $\mathbf{3}$, were most abundant in the basic fraction of jonquil

*Correspondence: Dr. B. Maurer

Firmenich $S A$

Research Laboratories

P.O. Box 239

CH-1211 Geneva 8

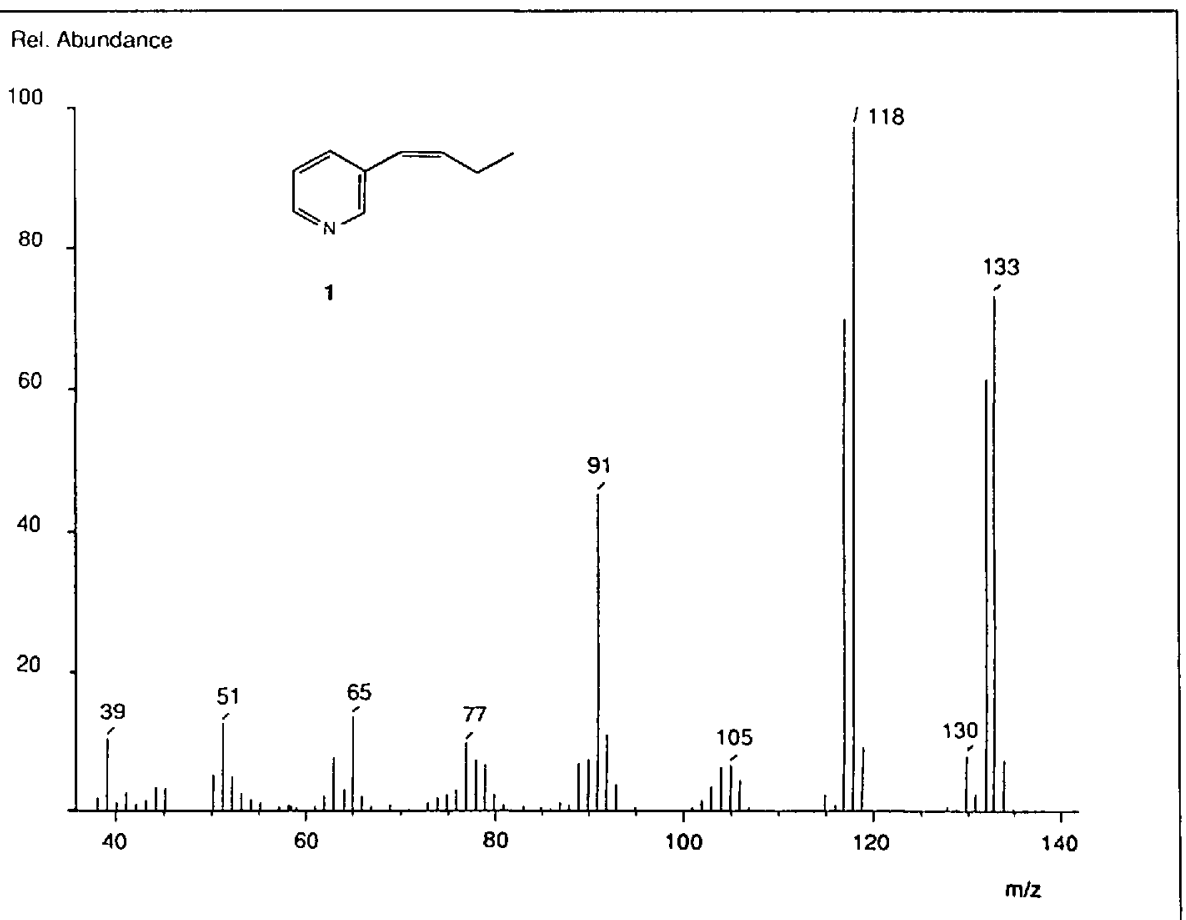

Fig. 1. Mass spectrum of 1

Rel. Abundance

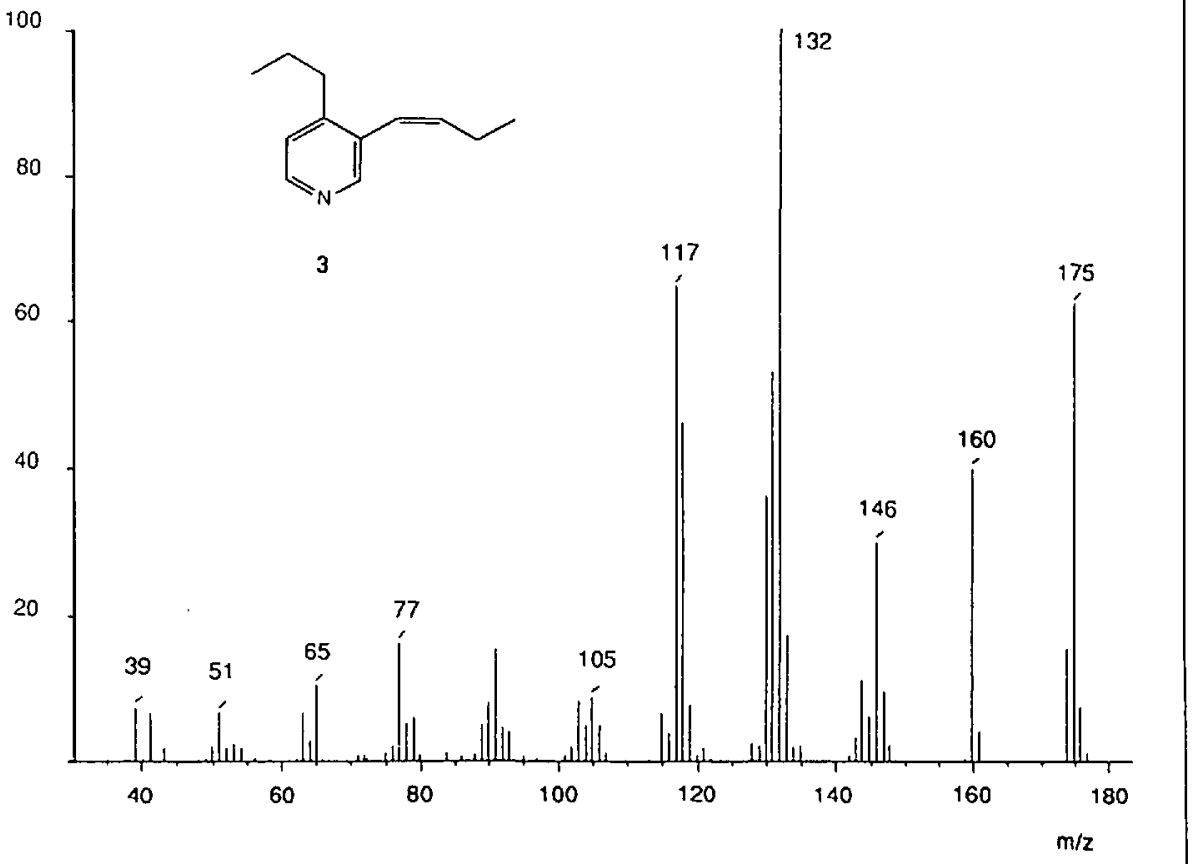

Fig. 2. Mass spectrum of 3 


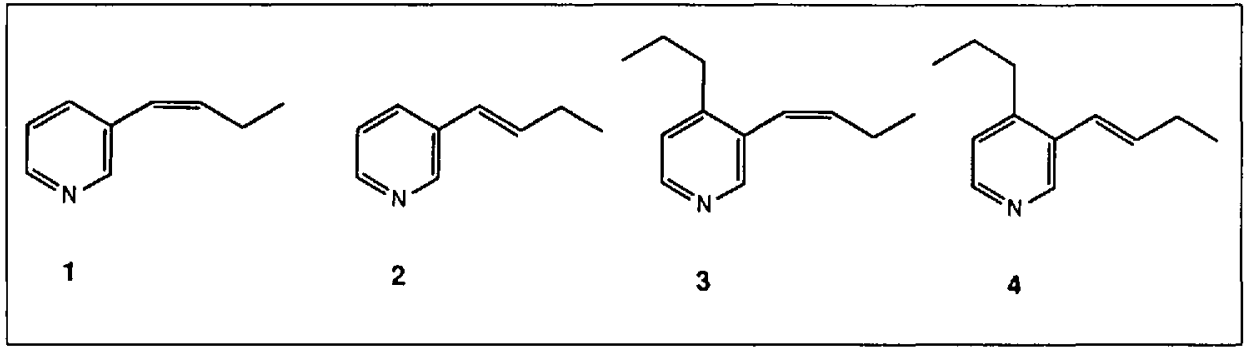

phenyl(propylidene)phosphorane gave a mixture of the $(Z)$-and the $(E)$-isomer, 1 and 2 , resp. (ratio 8:2), which were isolated pure by $\mathrm{GC}$ (silicone, $140^{\circ}$ ). The synthetic $(Z)$-isomer was identical $\left(\mathrm{GC},{ }^{1} \mathrm{H}\right.$ NMR, MS) to the natural compound 1 ; traces of the $(E)$-isomer 2 were detected (GC, MS) in the base fraction of jonquil abs. and patchouli oil. The concentrations of these pyridines in jonquil abs. can be estimated at $10 \mathrm{ppm}$ for 1 and $1 \mathrm{ppm}$ for 2 .

The 'H-NMR spectrum of the second unknown confirmed the empirical formula $\mathrm{C}_{12} \mathrm{H}_{17} \mathrm{~N}$ (17 protons) and suggested the presence of a 3,4-disubstituted pyridine with a $(Z)$-but-1-enyl and a $\operatorname{Pr}$ side chain. It seemed reasonable, in analogy to compound 1 , to leave the $\mathrm{C}_{4}$-substituent at $\mathrm{C}(3)$ and to place the $\operatorname{Pr}$ group at $\mathrm{C}(4)$ Structure 3 for the second unknown was confirmed by synthesis (Scheme 2).

The Grignard reaction of $\mathrm{PrMgBr}$ with the known nitrile 6 [1] in toluene gave, after acidic hydrolysis of the imine intermediate, the ketone 7 in $77 \%$ yield. Reduction of 7 , followed by acetylation, led to the acetate 9 which upon thermolysis at $500^{\circ}$ gave a $1: 5$ mixture ( $72 \%$ from 9 ) of the (Z)- and $(E)$-isomers 3 and 4 , resp. The pure isomers were isolated by $\mathrm{GC}$.

The $(Z)$-isomer 3 was identical $(\mathrm{GC}$, 'H-NMR, MS) with the unknown isolated from jonquil abs. (concentration ca. 20 ppm) and was also identified in trace amounts in the basic fraction of patchouli oil. The $(E)$-isomer 4 was also present in jonquil (GC, MS) at a level of $c a .10 \mathrm{ppm}$.

To our surprise, none of the four pyridines $1-4$ was known, although numerous

mono- and disubstituted pyridines have been identified as trace components of essential oils [2]. The presence of an unsaturated unbranched substituent of more than two C-atoms seems to be a new feature of such naturally occurring pyridines. It is known that pyridines and other basic components may play important roles in modulating the floral odours of the other ingredients of essential oils, e.g. in jasmin [3]. This is certainly also the case for 1-4 which have very strong pungent pyridine-like odours in concentrated form. When diluted, these compounds exhibit different nuances of green and flowery odours.

\section{Experimental}

General. All reactions were carried out under Ar. Org. extracts were dried over $\mathrm{MgSO}_{4}$ and evaporated at $40-50^{\circ}$ in a rotatory evaporator at reduced pressure. Anal. GC: $15 \mathrm{~m} \times 0.25 \mathrm{~mm}$ fused-silica-Supelcowax-10 (film thickness 0.25 $\mu \mathrm{m})$ or $10 \mathrm{~m} \times 0.25 \mathrm{~mm}$ fused-silica-SPB-5 $(0.25$ um) column. Prep. GC.: Carbowax 20 M, 2\% on Chromosorb $G$ (DMCS treated), 60-80 mesh $(4.1 \mathrm{~m} \times 4 \mathrm{~mm}$ ) and silicone $C E \mathrm{XE}-60,4 \%$ on Chromosorb $G$ (acid washed, DMCS treated) 60-80 mesh (4.1 m x 4 mm). IR: Perkin-Elmer 720 spectrometer. 'H-NMR (360 MHz): Bruker AM 360 instrument using TMS as internal standard. Chemical shifts $(\delta)$ are in ppm; coupling constants $(J)$ in Hz. MS: Finnigan 1020 automated GC/MS instrument, electron energy $70 \mathrm{eV}$ signals in $m / z$ (rel. \%).

Isolation from Jonquil Absolute. Distillation of commercial jonquil abs. $(500 \mathrm{~g}$, Chauvet, Grasse) in a short-path distillation apparatus (Leybold) gave a distillate $(365 \mathrm{~g}, 73 \%$, including the
Scheme 1

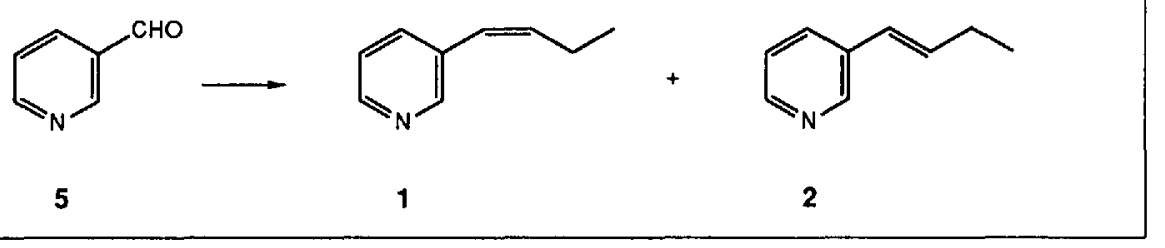

Scheme 2

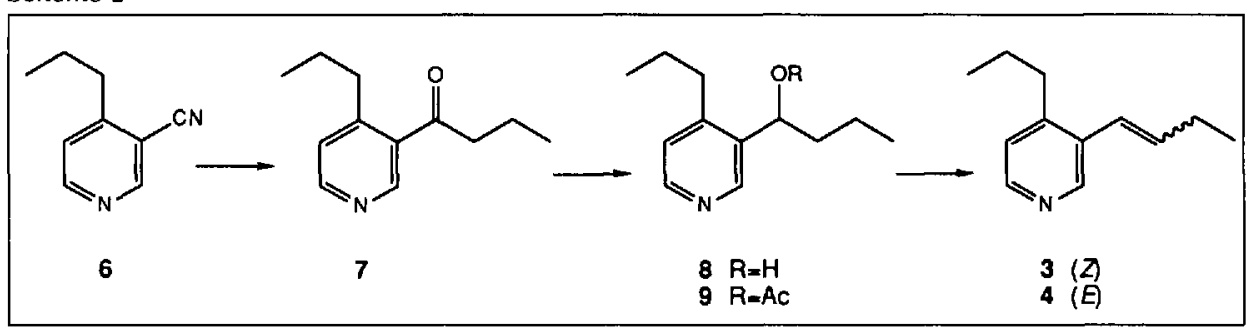

material collected in the cooling trap at $\left.-180^{\circ}\right)$, b.p. $<115^{\circ} / 0.01$ Torr). $\mathrm{Et}_{2} \mathrm{O} /$ pentane $1: 1$ (1200 $\mathrm{ml}$ ) was added to the distillate and the soln. was extracted in succession with sat. aq. $\mathrm{NaHCO}_{3}(5 \times$ $50 \mathrm{ml}), 10 \%$ aq. $\mathrm{Na}_{2} \mathrm{CO}_{3}(5 \times 50 \mathrm{ml}), 10 \%$ aq. $\mathrm{NaOH}(5 \times 50 \mathrm{ml})$, and $10 \%$ aq. $\mathrm{H}_{2} \mathrm{SO}_{4}(5 \times 50 \mathrm{ml})$. The combined $\mathrm{H}_{2} \mathrm{SO}_{4}$ extracts were washed with $\mathrm{Et}_{2} \mathrm{O}$ by continuous extraction for $20 \mathrm{~h}$ and basified with $10 \%$ aq. $\mathrm{NaOH}$. The alkaline soln. was continuously extracted with $\mathrm{Et}_{2} \mathrm{O}$ for $30 \mathrm{~h}$, and the $\mathrm{Et}_{2} \mathrm{O}$ soln. concentrated. The extract (crude bases, $50 \mathrm{mg}, 0.01 \%$ ) was analyzed by GC/MS and the two compounds 1 (10\% of crude bases) and $3(20 \%)$ were isolated by GC (Carbowax, $100-250^{\circ}, 4^{\circ} / \mathrm{min}$ ) for ${ }^{~} \mathrm{H}-\mathrm{NMR}$ spectra.

(Z)-3-(But-1-enyl)pyridine (1) and (E)-3(But-1-enyl)pyridine (2). $\mathrm{NaH}(3.7 \mathrm{~g}, 0.154 \mathrm{~mol})$ was stirred with dry DMSO $(50 \mathrm{ml})$ under Ar for 1 h at $70^{\circ}$. When the soln. had reached r.t., a soln. of triphenyl(propyl)phosphonium bromide $(44 \mathrm{~g}$, $0.11 \mathrm{~mol})$ in DMSO (150 ml) was added slowly, and the red soln. was stirred for $2.5 \mathrm{~h}$ at $20^{\circ} .3$ Pyridinecarbaldehyde (5; $11.7 \mathrm{~g}, 0.11 \mathrm{~mol}$, Fluka $A G$ ) was added dropwise at r.t. and stirring continued for $2 \mathrm{~h}$. The now colourless soln. was poured into ice-water, acidified with aq. $\mathrm{HCl}$ and the DMSO was extracted with several portions of $\mathrm{CH}_{2} \mathrm{Cl}_{2}$. The aq. phase was basified with aq. $\mathrm{NaOH}$, saturated with $\mathrm{NaCl}$, and extracted with $\mathrm{Et}_{2} \mathrm{O}$. Evaporation of the $\mathrm{Et}_{2} \mathrm{O}$ soln. gave a crude product which, after distillation (90-94\% $/ 10 \mathrm{Torr})$ through a Vigreux column, gave $10.5 \mathrm{~g}(71 \%)$ of a mix ture $1 / 2(8: 2)$. Distillation through a Fischer Spaltrohr column allowed partial separation of the isomers, which were isolated pure by GC (silicone, $140^{\circ}$ ). Both, the lower-boiling 1 and the higher-boiling 2 were identical (MS, GC, NMR) to the natural compounds.

Practically pure 1 was obtained in $92 \%$ yield, when the Wittig reaction was carried out under 'salt-free' conditions, $c f$. [4].

Data of 1: colourless oil. IR (film): $1635 w$, $1575 w, 1555 m, 1010 s, 810 s, 695 s$. MS: Fig. $l$. ${ }^{1} \mathrm{H}-\mathrm{NMR}\left(360 \mathrm{MHz}, \mathrm{CDCl}_{3}\right): 1.08(t, J=7.5$, $\left.\mathrm{CH}_{3}\right) ; 2.32\left(m, \mathrm{CH}_{2}\right) ; 5.80(\mathrm{t} d, J=7.5,11.5, \mathrm{H}-$ $\left.\mathrm{C}\left(2^{\prime}\right)\right) ; 6.34$ (br. $\left.d, J=11.5, \mathrm{H}-\mathrm{C}\left(1^{\prime}\right)\right) ; 7.25(d d, J$ $=8,5, \mathrm{H}-\mathrm{C}(5)) ; 7.57(t d, J=2,8, \mathrm{H}-\mathrm{C}(4)) ; 8.44$ $(d d, J=5,2, \mathrm{H}-\mathrm{C}(6)) ; 8.53(d, J=2, \mathrm{H}-\mathrm{C}(2))$.

Data of 2: colourless oil. IR (film): $1640 \mathrm{~m}$, $1575 w, 1560 s, 1405 s, 1115 m, 955 s, 835 m, 785 m$, 695s. MS: identical with $(Z)$-isomer. 'H-NMR $\left(360 \mathrm{MHz}, \mathrm{CDCl}_{3}\right): 1.11\left(t, J=7.5, \mathrm{CH}_{3}\right) ; 2.26$ $\left(m, \mathrm{CH}_{2}\right) ; 6.35\left(m, \mathrm{H}-\mathrm{C}\left(\mathrm{l}^{\prime}\right), \mathrm{H}-\mathrm{C}\left(2^{\prime}\right)\right) ; 7.2 \mathrm{l}$ (dd, $J=8,5, \mathrm{H}-\mathrm{C}(5)) ; 7.65(t d, J=2,8, \mathrm{H}-\mathrm{C}(4)) ; 8.42$ $(d d, J=5,2, \mathrm{H}-\mathrm{C}(6)) ; 8.55(d, J=2, \mathrm{H}-\mathrm{C}(2))$.

(Z)-3-(But-I-enyl)-4-propylpyridine (3) and (E)-3-(But-1-enyl)-4-propylpyridine (4). 1-(4Propylpyridin-3-yl)butan-1-one (7). To a soln. of $\operatorname{PrMgBr}(0.5 \mathrm{~mol})$ in toluene $(350 \mathrm{ml}, c f .[5])$ was added with stirring at r.t. within $5 \mathrm{~min}$ a soln. of 4-propyl-3-pyridinecarbonitrile (6) [1] (36.5 g, $0.25 \mathrm{~mol})$ in dry toluene $(50 \mathrm{ml})$. The soln. turned yellow and the exothermic reaction made the temperature rise to the boiling point. After $3 \mathrm{~h}$ at reflux, the suspension was allowed to reach r.t. and aq. $\mathrm{HCl}(6 \mathrm{~N}, 250 \mathrm{ml})$ was carefully added. The mixture was heated at reflux overnight, cooled at r.t., and the aq. phase was washed with $\mathrm{Et}_{2} \mathrm{O}$. The aq. phase was basified with $6 \mathrm{~N} \mathrm{NaOH}$ and extracted with $\mathrm{Et}_{2} \mathrm{O}$. Distillation (110\%0.01 Torr) of the crude product gave $36.7 \mathrm{~g}(77 \%)$ of 7 (purity by GC $>95 \%$ ). 
Data of 7: colourless liquid. IR (film): $1680 \mathrm{~s}$. MS: $191(3, M), 148(100), 130(13), 149$ (11), $120(9), 92(7), 118(6), 133(5), 65(4)$. 'H-NMR $\left(360 \mathrm{MHz}, \mathrm{CDCl}_{3}\right): 0.97,1.01\left(2 t, J=7,2 \times \mathrm{CH}_{3}\right)$; $1.62\left(m, \mathrm{CH}_{2}\right) ; 1.76\left(m, \mathrm{CH}_{2}\right) ; 2.80\left(m, \mathrm{CH}_{2}\right) ; 2.90$ $\left(i, J=7, \mathrm{CH}_{2}\right) ; 7.19(d, J=5, \mathrm{H}-\mathrm{C}(5)) ; 8.54(d, J$ $=5, \mathrm{H}-\mathrm{C}(6)) ; 8.82(s, \mathrm{H}-\mathrm{C}(2))$.

I-(4-Propylpyridin-3-yl)butan-I-ol (8). A soln. of $\mathrm{NaBH}_{4}(10 \mathrm{~g}, 0.26 \mathrm{~mol})$ in $\mathrm{H}_{2} \mathrm{O}(100 \mathrm{ml})$ was added at r.t. to a soln. of $7(19.1 \mathrm{~g}, 0.10 \mathrm{~mol})$ in $\mathrm{MeOH}(120 \mathrm{ml})$. The mixture was stirred for 4 $h$ at r.t., the solvents evaporated, and the residue dissolved in $\mathrm{H}_{2} \mathrm{O}$. The product was isolated by extraction with $\mathrm{Et}_{2} \mathrm{O}$ followed by bulb-to-bulb distillation $(130 \% .01$ Torr). Yield: $16 \mathrm{~g}(83 \%)$ of 8.

Data of 8 : colourless oil. IR (fil 1 ): 3300 (br. s), $1590 \mathrm{~m}$. 'H-NMR $\left(60 \mathrm{MHz}, \mathrm{CDCl}_{3}\right)$ : characteristic signals at 4.6 (br., $1 \mathrm{H}$, disappears with $\left.\mathrm{D}_{2} \mathrm{O}, \mathrm{OH}\right) ; 4.94(m, \mathrm{H}-\mathrm{C}-\mathrm{O})$. MS: $193(6, M)$ $150(100), 132(54), 117(93), 151(11), 118(10)$, $91(8)$.

1-(4-Propylpyridin-3-yl)butyl Acetate (9). This acetate was obtained in quant. yield by acetylation of 8 with $\mathrm{Ac}_{2} \mathrm{O}$ /pyridine (I:1) (r.t., overnight), followed by bulb-to-bulb distillation (120\%/0.01Torr).

Data of 9: colourless oil. IR (film): 1745s, 1245s. 'H-NMR (60 MHz, $\left.\mathrm{CDCl}_{3}\right)$ : characteristic signals at $2.05(s, \mathrm{Ac}) ; 6.02(d d, J=8,6, \mathrm{H}-\mathrm{C}-$ O). MS: $235(M,<1), 43(100), 45(86), 60(56)$, $150(26), 132(11), 175(7)$.

Pyrolysis of Acetate 9. A soln. of acetate 9 $(6.47 \mathrm{~g}, 27.5 \mathrm{mmol})$ in toluene $(30 \mathrm{ml})$ was pyrolyzed at $500^{\circ}$ at $c a .20$ Torr in a slow stream of $\mathrm{Ar}$ in a pyrolysis tube packed with quartz fragments. The crude pyrolysate was subjected to bulb-to-bulb distillation to give $3.5 \mathrm{~g}(72 \%)$ of $3 /$ 4 (1:5). The pure isomers were isolated by GC (silicone, $200^{\circ}$ ), 3 being eluted first.

Data of 3: colourless oil. IR (film): $1630 w$, 1580m, 1545w, 825m. MS: Fig. 2. ' $\mathrm{H}-\mathrm{NMR}(360$ $\left.\mathrm{MHz}, \mathrm{CDCl}_{3}\right): 0.94\left(t, J=7, \mathrm{CH}_{3}\left(3^{\prime \prime}\right)\right) ; 1.01(t, J$ $\left.=7.5, \mathrm{CH}_{3}\left(4^{\prime}\right)\right) ; 1.59\left(m, \mathrm{CH}_{2}\left(2^{\prime \prime}\right)\right) ; 2.13(m$, $\left.\mathrm{CH}_{2}\left(3^{\prime}\right)\right) ; 2.54\left(t, J=7.5, \mathrm{CH}_{2}\left(1^{\prime \prime}\right)\right) ; 5.82(t d, J=$ $\left.7.5,11, \mathrm{H}-\mathrm{C}\left(2^{\prime}\right)\right) ; 6.37$ (br. $d, J=11, \mathrm{H}-\mathrm{C}\left(1^{\prime}\right)$ ); $7.09(d, J=5, \mathrm{H}-\mathrm{C}(5)) ; 8.34(s, \mathrm{H}-\mathrm{C}(2)) ; 8.37(d$, $J=5, \mathrm{H}-\mathrm{C}(6))$.

Data of 4: colourless oil. IR (film): $1640 w$, $1585 s, 1545 w, 960 s, 830 m$. MS: practically identical with spectrum of the $(Z)$-isomer. ${ }^{1} \mathrm{H}-\mathrm{NMR}$ $\left(360 \mathrm{MHz}, \mathrm{CDCl}_{3}\right): 0.97\left(t, J=7, \mathrm{CH}_{3}\left(3^{\prime \prime}\right)\right) ; 1.12$ $\left(t, J=7.5, \mathrm{CH}_{3}\left(4^{\prime}\right)\right) ; 1.62\left(m, \mathrm{CH}_{2}\left(2^{\prime \prime}\right)\right) ; 2.27(m$, $\left.\mathrm{CH}_{2}\left(3^{\prime}\right)\right) ; 2.61\left(t, J=7.5, \mathrm{CH}_{2}\left(1^{\prime \prime}\right)\right) ; 6.19(t d, J=$ $\left.6.5,16, \mathrm{H}-\mathrm{C}\left(2^{\prime}\right)\right) ; 6.51$ (br. $\left.d, J=16, \mathrm{H}-\mathrm{C}\left(1^{\prime}\right)\right)$; $7.02(d, J=5, \mathrm{H}-\mathrm{C}(5)) ; 8.33(d, J=5, \mathrm{H}-\mathrm{C}(6))$; $8.57(s, \mathrm{H}-\mathrm{C}(2))$.

Received: January 24, 1992

[1] L. Chevolot, H.-P. Husson, P. Potier, Tetrahedron 1975, 31, 2491.

[2] See e.g. D. Lamparsky, I. Klimes, Perfumer Flavorist 1988, 13, 17, and ref. cit. therein; K. Sakurai, K. Takahashi, T. Yoshida, Agric. Biol. Chem. 1983, 47, 2307; G. Vernin, Perfumer Flavorist 1982, 7, 23.

[3] T. Toyoda, S. Muraki, T.Yoshida, Agric. Biol. Chem. 1978, 42, 190 I.

[4] M. Schlosser, K.F. Christmann, Liebigs Ann. Chem. 1967, 708, 1.

[5] J.E. Callen, C.A. Dornfeld, G.H. Coleman, Org. Synth. Coll. Vol. 3 1955, 26.

\section{Acetoxymaleic Anhydride as Ketene Equivalent in the Diels-Alder Reaction}

\section{Ernest Wenkert $\left.{ }^{\mathfrak{a}}\right)^{*}$, Christian Vial $^{\mathrm{b}}$ ), and Ferdinand Näf $\left.{ }^{\mathrm{b}}\right)^{*}$}

Abstract. Acetoxymaleic anhydride (AMA) has been shown to be a versatile ketene equivalent in the Diels-Alder reaction for the conversion of 1,3-dienes into cyclohexanones. The new transformation has been applied to an alternate synthesis of methyl cis-dihydrojasmonate, an important jasmine fragrance, and to several model systems. but react in a [4+2] mode with 1,3-dienes are most useful building blocks [ 1$]$.

In this publication, we describe the use of acetoxymaleic anhydride (AMA, 1) [2] as ketene equivalent in the Diels-Alder reaction (Scheme 1 ).

The known reaction of AMA (1) with cyclopentadiene 2 gave the adduct $3(82 \%)$ [3]. It was assumed that acetoxyglutaric anhydride 3 or its dihydro derivative 4 would undergo hydrolytic decarbonylation in analogy to the behavior of $\alpha$-oxyacids, which lose $\mathrm{CO}$ upon acid treatment forming carbonyl compounds [4] (Scheme 2 ). When the saturated acetoxyglutaric anhydride 4 [5] was treated with $96 \%$ $\mathrm{H}_{2} \mathrm{SO}_{4}$ between 5 and $20^{\circ}$, a $42: 58$ mixture $(57 \%)$ of $5 \mathbf{a}$ and $5 \mathrm{~b}$, was obtained (Scheme 1). Acid-catalysed decarboxylation of the
Six-membered ring compounds cannot be obtained from simple ketenes and 1,3-dienes via a [4+2] cycloaddition reaction, since ketenes undergo exclusively $[2+2]$ cycloaddition leading to four-membered ring structures instead. Therefore, synthons which are equivalent to ketenes

\footnotetext{
* Correspondence: Prof. E. Wenkert, Dr. F. Näf a) University of California - San Diego Department of Chemistry (0506) 9500 Gilman Drive La Jolla, California 92093, USA

b) Firmenich $S A$

Research Laboratories

P.O. Box 239

CH-1211 Geneva 8
}

Scheme I

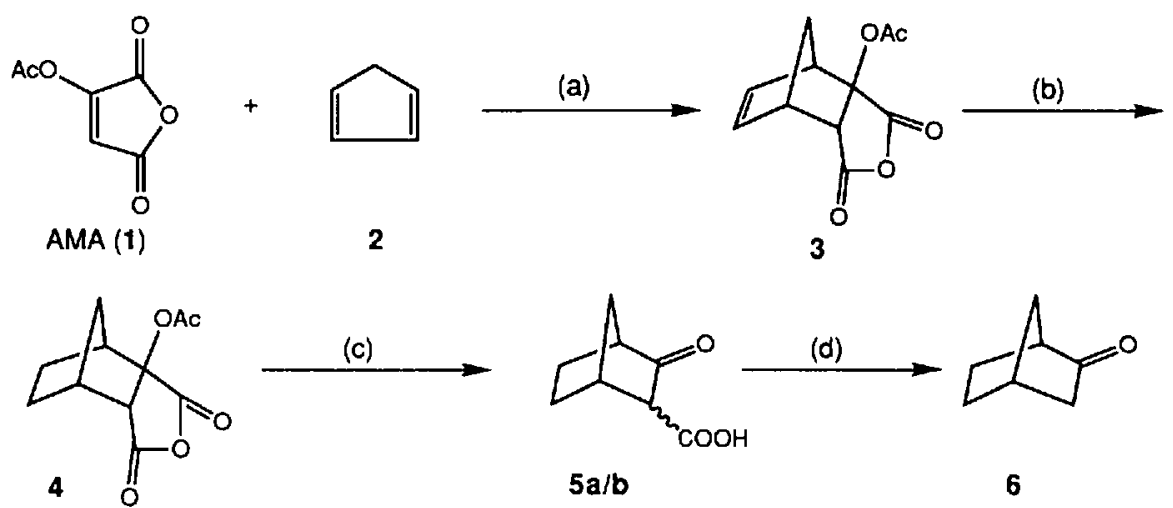

Reagents: a) $24 \mathrm{~h} / 25^{\circ}$, benzene; b) $\mathrm{H}_{2} / \mathrm{Pd}-\mathrm{C}$; c) $96 \% \mathrm{H}_{2} \mathrm{SO}_{4} / 5^{\circ} \rightarrow 25^{\circ}$; d) $\mathrm{AcOH}, 2$ h reflux 